\title{
Universiteit
}

Leiden

The Netherlands

\section{Challenges in reduction of dinitrogen by proton and electron transfer} Ham, C.J.M. van der; Koper, M.T.M.; Hetterscheid, D.G.H.

\section{Citation}

Ham, C. J. M. van der, Koper, M. T. M., \& Hetterscheid, D. G. H. (2014). Challenges in reduction of dinitrogen by proton and electron transfer. Chemical Society Reviews, 43(15), 5183-5191. doi:10.1039/C4CS00085D

Version: $\quad$ Publisher's Version

License: $\quad$ Licensed under Article 25fa Copyright Act/Law (Amendment Taverne)

Downloaded from: https://hdl.handle.net/1887/3238681

Note: To cite this publication please use the final published version (if applicable). 


\section{Chem Soc Rev}

Cite this: Chem. Soc. Rev., 2014 43,5183

Received 25th February 2014

DOI: $10.1039 / \mathrm{c} 4 \mathrm{cs} 00085 \mathrm{~d}$

www.rsc.org/csr

\section{Challenges in reduction of dinitrogen by proton and electron transfer}

\author{
Cornelis J. M. van der Ham, Marc T. M. Koper and Dennis G. H. Hetterscheid*
}

\begin{abstract}
Ammonia is an important nutrient for the growth of plants. In industry, ammonia is produced by the energy expensive Haber-Bosch process where dihydrogen and dinitrogen form ammonia at a very high pressure and temperature. In principle one could also reduce dinitrogen upon addition of protons and electrons similar to the mechanism of ammonia production by nitrogenases. Recently, major breakthroughs have taken place in our understanding of biological fixation of dinitrogen, of molecular model systems that can reduce dinitrogen, and in the electrochemical reduction of dinitrogen at heterogeneous surfaces. Yet for efficient reduction of dinitrogen with protons and electrons major hurdles still have to be overcome. In this tutorial review we give an overview of the different catalytic systems, highlight the recent breakthroughs, pinpoint common grounds and discuss the bottlenecks and challenges in catalytic reduction of dinitrogen.
\end{abstract}

Key learning points

(1) Three different reaction mechanisms are described for nitrogen reduction: a dissociative, an alternating associative and a distal associative pathway.

(2) The binding strength of nitrogen to the catalyst is of key importance for the selectivity for ammonia synthesis. As the nitrogen atoms bind weaker to the metal, an increase in the activity for hydrogen evolution is observed.

(3) A higher binding strength of nitrogen to the catalyst comes at the expense of a higher overpotential requirement. An optimum between the overpotential required and the selectivity must be found in order to energetically compete with the Haber-Bosch process.

(4) At this moment, the Haber-Bosch process is still the most efficient process available for the synthesis of ammonia.

\section{Introduction}

Nitrogen is essential for life since it is part of important building blocks such as amino acids and nucleotides. ${ }^{1}$ Even though dinitrogen is very abundant in the earth's atmosphere; it can only be used for biosynthesis after it has been converted to ammonia. In nature, this ability to fix ammonia is restricted to a small group of diazotrophic microorganisms. ${ }^{2}$ Fixation of dinitrogen has been shown to be a very difficult reaction, even though the conversion of dinitrogen and dihydrogen is exothermic at standard conditions. This is because the $\mathrm{N} \equiv \mathrm{N}$ triple bond is very strong and difficult to activate due to the absence of a permanent dipole. ${ }^{3}$ Consequently, uncatalyzed reduction of dinitrogen is difficult and even with the best catalysts known to date a substantial energy input is required to activate dinitrogen. In the Haber-Bosch synthesis of ammonia, heterogeneous iron or ruthenium catalysts are used at temperatures from 300 to $500{ }^{\circ} \mathrm{C}$ in order to break the $\mathrm{N} \equiv \mathrm{N}$ bond with sufficient rates and to convert dinitrogen to ammonia in the

Leiden Institute of Chemistry, Leiden University, Einsteinweg 55, 2333 CC Leiden, The Netherlands. E-mail: d.g.h.hetterscheid@chem.leidenuniv.nl;

Fax: +31 715274451; Tel: +31715274545 presence of dihydrogen. ${ }^{4}$ At such high temperatures the ammonia yield is very low due to the unfavorable position of the equilibrium, which lies all the way towards formation of $\mathrm{N}_{2}$ and $\mathrm{H}_{2}$. Hence, the Haber-Bosch synthesis of ammonia is carried out at pressures of 200-300 atmosphere to shift the equilibrium towards production of ammonia. ${ }^{4}$ Due to these reaction conditions the ammonia synthesis requires an energy input of roughly $485 \mathrm{~kJ} \mathrm{~mol}^{-1}$. 5,6 Since the Haber-Bosch synthesis of ammonia is carried out on a tremendous scale, about $1.4 \%$ of all energy consumed by mankind is invested into this process alone. ${ }^{5}$ A less energy consuming alternative would be highly desirable.

Nitrogen fixation in nature occurs through multiple proton and electron transfer steps. High temperatures are not required for this reaction, avoiding unfavorable equilibrium issues. Nevertheless, also in nature a significant energy input is required, which is delivered by ATP. ${ }^{2}$ Inspired by the natural process one could envisage dinitrogen fixation to occur upon addition of protons and electrons, whereby the thermodynamic driving force is controlled by an electrochemical potential. In this case ammonia production can take place at room temperature, where the equilibrium between ammonia and dinitrogen is favorable. A few attempts to produce ammonia via such an approach 
have been described in the past, yet thus far have not been able to replace the Haber-Bosch process. With increasing energy consumption and carbon dioxide related global climate change in mind, in this review catalytic dinitrogen fixation by transfer of protons and electrons is evaluated as a potential alternative to the energy intense Haber-Bosch reaction. To carefully address the major bottlenecks in catalytic dinitrogen reduction upon addition of protons and electrons, we will first highlight the $\mathrm{N}_{2}$ fixation process by nitrogenases, molecular inorganic catalysts and at heterogeneous surfaces. Based on this comparison we will determine where major challenges lie and discuss whether electrochemical reduction of dinitrogen could be an alternative to the Haber-Bosch reaction.

\section{Dinitrogen reduction by nitrogenases}

In nature nitrogenases reduce dinitrogen to ammonia, which is subsequently used in the synthesis of for example amino acids and nucleotides. ${ }^{2}$ Reduction of dinitrogen at the more successful nitrogenases occurs at a FeMo cofactor, which consists of

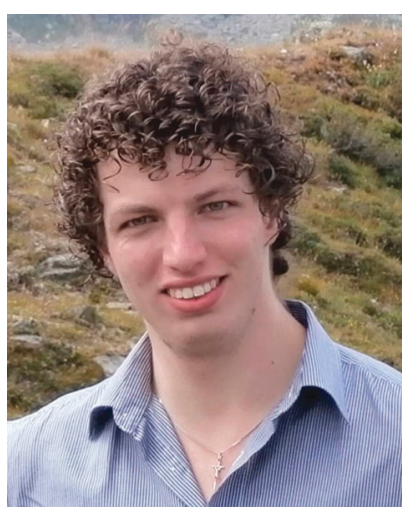

Koen van der Ham finished his BSc Molecular Science and Technology at Leiden University and the Technical University of Delft in 2011. In 2013 he obtained his MSc degree in Chemistry from Leiden University. Currently, he is a PhD student in the group of $\mathrm{Dr}$ Hetterscheid, working on molecular catalysts for the oxidation of water.

Cornelis J. M. van der Ham

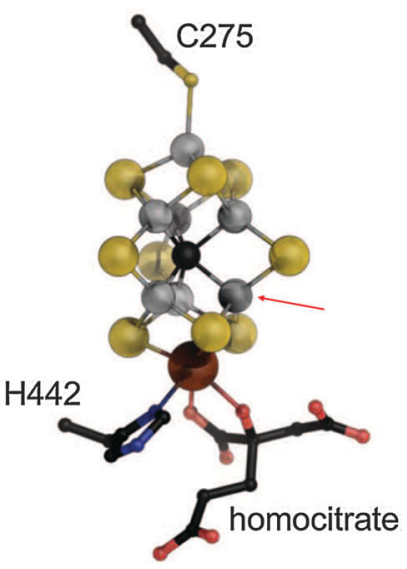

Fig. 1 Structure of the FeMo cofactor of nitrogenase showing the iron centers in metallic, the sulfur atoms in gold, the molybdenum center in red and the central carbon atom in black. The postulated binding site of dinitrogen is marked with an arrow. Reprinted with permission from AAAS. ${ }^{8}$

two fused iron-sulfur clusters, of which a molybdenum atom takes up one of the apical positions (Fig. 1). ${ }^{7}$ In the middle of both clusters a light atom is located, which was recently revealed to be a carbon atom. ${ }^{8,9}$ The enzymatic reduction of dinitrogen by the FeMo nitrogenase is not the most efficient reaction and requires consumption of 16 equivalents of ATP per $\mathrm{N}_{2}$ molecule, even though the synthesis of ammonia is an exothermic reaction (eqn (1)). Per $\mathrm{NH}_{3}$ molecule, 8 ATP molecules are consumed, equivalent to $244 \mathrm{~kJ} \mathrm{~mol}^{-1}$, making it more efficient than the Haber-Bosch process. ${ }^{10}$

$\mathrm{N}_{2}+8 \mathrm{H}^{+}+8 \mathrm{e}^{-}+16 \mathrm{ATP} \rightarrow 2 \mathrm{NH}_{3}+\mathrm{H}_{2}+16 \mathrm{ADP}+16 \mathrm{P}_{\mathrm{i}}$

For every molecule of dinitrogen that is reduced at least one equivalent of dihydrogen is produced. This stoichiometry was found at a partial dinitrogen pressure of 50 atmosphere, ${ }^{11}$ while at ambient pressure substantially more dihydrogen is formed. ${ }^{2}$ This implies that under these conditions additional equivalents

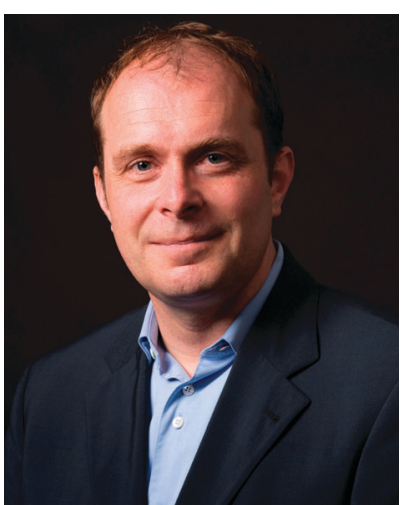

Marc T. M. Koper
Marc T. M. Koper is Professor of Surface Chemistry and Catalysis at Leiden University, The Netherlands. He received his PhD degree (1994) from Utrecht University (The Netherlands) in the field of electrochemistry. $\mathrm{He}$ was an EU Marie Curie postdoctoral fellow at the University of Ulm (Germany) and a Fellow of Royal Netherlands Academy of Arts and Sciences (KNAW) at Eindhoven University of Technology, before moving to Leiden University in 2005. His main research interests are in fundamental aspects of electrocatalysis, theoretical electrochemistry, and electrochemical surface science.

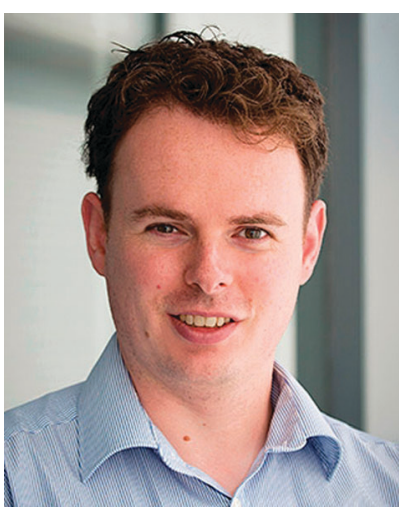

Dennis G. H. Hetterscheid
Dennis Hetterscheid obtained his PhD at the University of Nijmegen under supervision of Prof. De Bruin in 2007. He was a postdoctoral fellow in the groups of Prof. Schrock at the Massachusetts Institute of Technology and Prof. Reek at the University of Amsterdam. Currently he is a tenure track assistant professor in "physical chemistry of sustainable energy" at Leiden University. The main research in his group considers small molecule activation

through multi-redox processes. Focus lies especially with fundamental understanding of these problems, which are tackled by means of a mixed synthetic, electrochemical and theoretical approach. 
of ATP must be consumed to convert one molecule of dinitrogen to two molecules of ammonia, increasing the energy consumption. ${ }^{12}$ Besides FeMo, also FeV and Fe-only nitrogenases exist. These systems have been studied in much less detail and produce substantially more dihydrogen compared to the parent FeMo system. ${ }^{2}$ Why nitrogenases produce dihydrogen and how dihydrogen and ammonia are formed simultaneously is a matter of ongoing debate. Hydrogen is a weak inhibitor for catalytic turnover of dinitrogen. ${ }^{13,14}$ Hydrogen production at FeMo nitrogenase under a $\mathrm{D}_{2}$ atmosphere reveals formation of $\mathrm{HD}$, indicating that scrambling of $\mathrm{H}^{+}$with $\mathrm{D}_{2}$ occurs. ${ }^{13,14}$ Formation of $\mathrm{HD}$ increases with increase of the partial dinitrogen pressure, suggesting that hydrogen scrambling somehow must be dependent on turnover of dinitrogen. This suggests that formation of dihydrogen is not just a side reaction in the formation of ammonia, but its formation must be an intrinsic phenomenon of catalytic dinitrogen reduction in nitrogenases.

Catalytic experiments with mutant strains point to one of the iron atoms adjacent to molybdenum as a possible binding site for dinitrogen, which is indicated in Fig. 1 with an arrow. See ref. 15 for a more elaborate discussion on possible binding sites of dinitrogen.

Based on the reaction stoichiometry, kinetic experiments, trapping of catalytic intermediates to the cofactor and catalytic reduction of intermediate hydrazine and diazene, a reaction mechanism was proposed by Hoffman, Seefeldt and Dean. ${ }^{13,15}$ Prior to coordination of dinitrogen, four protons and four electrons are accumulated at the FeMo cofactor. In absence of $\mathrm{N}_{2}$, two equivalents of $\mathrm{H}_{2}$ are formed and the enzyme falls back into its resting state. In the presence of dinitrogen, reductive elimination of $\mathrm{H}_{2}$ must occur prior to coordination of $\mathrm{N}_{2}$. From the adsorption of $\mathrm{N}_{2}$, two different pathways wherein further reduction of dinitrogen can occur are described, i.e. the distal (D) and alternating (A) pathway displayed in Fig. 2. In the distal pathway, the remote nitrogen atom is hydrogenated first and released as $\mathrm{NH}_{3}$. Only once the first equivalent of ammonia is released, protons add to the remaining nitrido species to produce the second molecule of ammonia and thereby close the catalytic cycle.

In the alternating pathway, both $\mathrm{N}$-atoms are hydrogenated simultaneously, and release of ammonia proceeds after addition of five and six protons to the dinitrogen fragment. Diazene and hydrazine were shown to be excellent substrates for the production of ammonia, and suggest that the diazene, hydrazido and hydrazine intermediates must be accessible. ${ }^{13}$ This alone does not prove that formation of ammonia occurs via the alternating pathway, as shunts from these diazene and hydrazine intermediates to intermediates that lie on the distal route may be possible. $\mathrm{FeV}$ nitrogenases, which are believed to operate via the same

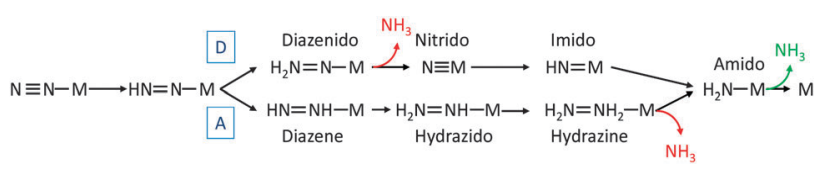

Fig. 2 Proposed mechanism of reduction of dinitrogen at FeMo nitrogenase. mechanism as FeMo nitrogenases, produce traces of hydrazine and most likely operate via an alternating associative pathway. ${ }^{16}$

\section{Molecular catalysts for the reduction of dinitrogen}

So far the most successful artificial and molecular systems for the reduction of dinitrogen are molybdenum based. Already in the seventies, Chatt proposed a catalytic mechanism for dinitrogen reduction at molybdenum phosphine complexes. ${ }^{17}$ Although the proposed mechanism was based on several isolated molybdenum complexes with partly reduced dinitrogen intermediates coordinated, no catalytic turnover was obtained for this system. Catalytic reduction of dinitrogen was achieved by Yandulov and Schrock using a steric crowded trisamidoamine ligand for coordination to molybdenum in combination with bulky pyridinium salts as a proton source. Decamethylchromocene was used as a sacrificial reducing agent. ${ }^{18}$ A yield of $67 \%$ in ammonia was obtained which is higher than that of the natural system under ambient conditions. ${ }^{2}$ The Schrock system is remarkable, as most species of the proposed catalytic cycle have been isolated and were thoroughly characterized, while attempts to isolate the remaining transient species resulted in disproportionation reactions leading to other intermediates of the catalytic cycle and formation of ammonia. ${ }^{19,20}$ As a result a very clear picture has emerged on how catalytic reduction of dinitrogen occurs at these trisamidoamine molybdenum systems. ${ }^{21}$ Dinitrogen coordinates in an end-on fashion to molybdenum and reduction to ammonia occurs via a distal associative mechanism, wherein the catalytic intermediates are sequentially protonated and reduced as displayed in Fig. 3. The addition of the first proton and equivalent of reducing agent to the dinitrogen complex is an exception. Protonation of this species with pyridinium salts is difficult, whereas reduction of the molybdenum dinitrogen intermediate

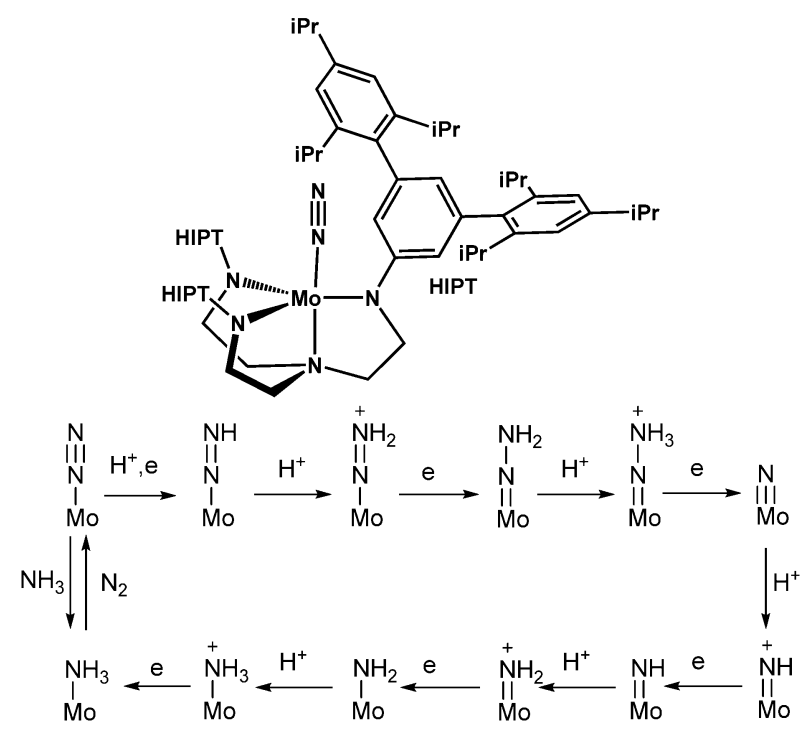

Fig. 3 Structure and catalytic cycle for trisamidoamine molybdenum catalysts with hexaisopropylterphenyl (HIPT) substituents. ${ }^{18}$ 
occurs at $-1.81 \mathrm{~V}$ versus the ferrocene/ferrocenium redox couple. Since the redox potential of decamethylchromocene is $-1.47 \mathrm{~V}$, it is believed that the first reduction step proceeds via a proton-coupled electron transfer (PCET) mechanism. ${ }^{22}$ The resulting MoNNH species is the most sensitive of the entire reaction mechanism, and in absence of sufficient steric bulk rapidly produces $\mathrm{H}_{2}$ via a $\beta$-elimination reaction of hydrogen. ${ }^{23}$ This leads to fast formation of dihydrogen and regeneration of the initial dinitrogen complex. Apparently, dihydrogen formation is not simply a side reaction of nitrogen fixation, but may also occur intrinsically upon decomposition of partly reduced intermediates of the catalytic cycle. Displacement of ammonia for dinitrogen is the rate determining step of the catalytic reaction. ${ }^{17,18}$

Similar to the natural system, hydrogen is an inhibitor for catalytic activity as it coordinates stronger to molybdenum than dinitrogen and ammonia. ${ }^{24}$ Formation of dihydrogen can be largely prevented by dropwise addition of the reducing agent, in combination with a poorly soluble acid. ${ }^{18}$ Using the same strategy Nishibayashi managed to significantly increase the number of turnovers per equivalent of molybdenum to $12 \mathrm{using}$ a PNP pincer ligand (Fig. 4). ${ }^{25}$ Based on the reducing agents and acids used one can determine that the amount of energy that is required to reduce one equivalent of dinitrogen to two equivalents of ammonia. ${ }^{26}$ The numbers for the Schrock system (580 $\mathrm{kJ} \mathrm{mol}^{-1}$ calculated from a $65 \%$ efficiency) and the Nishibayashi system (700 $\mathrm{kJ} \mathrm{mol}^{-1}$ at $50 \%$ efficiency) are higher, but in the same ballpark as the required energy input in case of the HaberBosch reaction.

Since the binding site for dinitrogen at FeMo nitrogenases may be iron based and is certainly iron based at Fe-only nitrogenases, several iron complexes have been studied for catalytic reduction of dinitrogen. One of the most notable systems was reported by Peters et al., using tetradentate trisphosphinosilyl ligands to stabilize the iron center (Fig. 4). ${ }^{27}$ Several iron complexes bearing partly reduced dinitrogen intermediates such as $\mathrm{Fe}-\mathrm{N}_{2}, \mathrm{Fe}-\mathrm{NH}_{2} \mathrm{NH}_{2},\left(\mathrm{Fe}-\mathrm{NH}_{2} \mathrm{NHPh}\right)^{+}, \mathrm{Fe}-\mathrm{NH}_{2} \mathrm{NHPh}$, $\mathrm{Fe}-\mathrm{NNSiMe}_{3}$ and $\mathrm{Fe}-\mathrm{NH}_{3}$ were fully characterized, and suggest that catalytic reduction of dinitrogen at this Fe species may be possible via an associative pathway. Treatment of the iron complex with a very strong reducing agent (potassium graphite) and a very strong acid $\left(\left[\mathrm{H}\left(\mathrm{OEt}_{2}\right)_{2}\right]\left[\left(3,5-\left(\mathrm{CF}_{3}\right)_{2} \mathrm{C}_{6} \mathrm{H}_{3}\right)_{4} \mathrm{~B}\right]\right)$ results in catalytic formation of ammonia. ${ }^{28}$
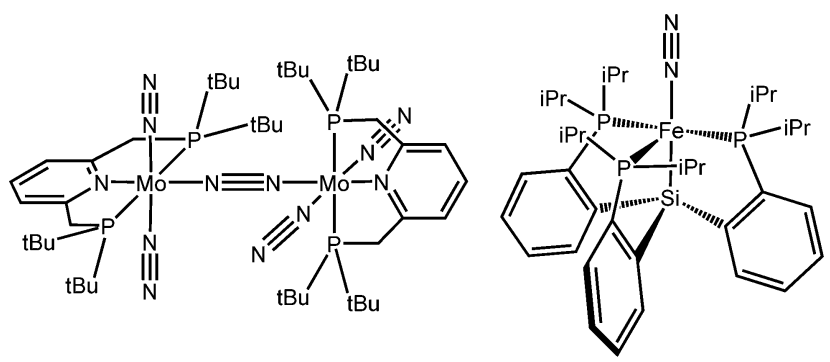

Fig. 4 Structure of the molybdenum catalysts by Nishibayashi et al. (left) and the iron catalyst of Peters and coworkers (right).
For comprehensive reviews on complexes related to the reduction of dinitrogen the reader is referred to several excellent reviews that appeared recently. ${ }^{29-31}$

\section{Electrochemical reduction of dinitrogen}

\subsection{Thermodynamics of electrochemical dinitrogen} reduction

Some of the fundamental bottlenecks in the electrochemical reduction of dinitrogen by PCET can be understood on the basis of the thermodynamic constraints imposed by the intermediates of the reaction. Some of these intermediates feature in the mechanisms discussed in the preceding section. The overall reaction under consideration is:

$$
\mathrm{N}_{2}+6 \mathrm{H}^{+}+6 \mathrm{e}^{-} \leftrightarrows 2 \mathrm{NH}_{3}(\mathrm{~g}) \quad E^{0}=-0.148 \mathrm{~V} \text { vs. RHE }
$$

where we have chosen the equilibrium potential corresponding to alkaline media, and employ the reversible hydrogen electrode (RHE) as reference.

The equilibrium potentials of two important intermediates, hydrazine $\left(\mathrm{N}_{2} \mathrm{H}_{4}\right)$ and diazene $\left(\mathrm{N}_{2} \mathrm{H}_{2}\right)$ are also known: ${ }^{32,33}$

$$
\begin{aligned}
& \mathrm{N}_{2}+4 \mathrm{H}^{+}+4 \mathrm{e}^{-} \leftrightarrows \mathrm{N}_{2} \mathrm{H}_{4}(\mathrm{~g}) \quad E^{0}=-0.33 \mathrm{~V} \text { vs. RHE } \\
& \mathrm{N}_{2}+2 \mathrm{H}^{+}+2 \mathrm{e}^{-} \leftrightarrows \mathrm{N}_{2} \mathrm{H}_{2}(\mathrm{~g}) \quad E^{0}=-1.10 \mathrm{~V} v s . \mathrm{RHE}
\end{aligned}
$$

These negative equilibrium potentials, especially that of diazene, illustrate the thermodynamic difficulty of hydrogenating $\mathrm{N}_{2}$. The equilibrium potentials of the very first electron transfer have also been estimated: $:^{32,33}$

$$
\begin{aligned}
\mathrm{N}_{2}+\mathrm{H}^{+}+\mathrm{e}^{-} \leftrightarrows \mathrm{N}_{2} \mathrm{H}(\mathrm{g}) \quad E^{0} \approx-3.2 \mathrm{~V} v s . \mathrm{RHE} \\
\mathrm{N}_{2}+\mathrm{e}^{-} \leftrightarrows \mathrm{N}_{2}^{-}(\mathrm{aq}) E^{0} \approx-4.16 \mathrm{~V} \text { vs. NHE or } \\
E^{0} \approx-3.37 \mathrm{~V} \text { vs. RHE at } \mathrm{pH}=14
\end{aligned}
$$

A likely first step in the mechanism of dinitrogen reduction by PCET is the formation of a catalyst-bound $\mathrm{N}_{2} \mathrm{H}^{*}$ species. A likely last step in the mechanism is the desorption of the $\mathrm{NH}_{2}{ }^{*}$ species:

$$
\begin{gathered}
\mathrm{N}_{2}+\mathrm{H}^{+}+\mathrm{e}^{-} \leftrightarrows \mathrm{N}_{2} \mathrm{H}^{*} \\
\mathrm{NH}_{2}^{*}+\mathrm{H}^{+}+\mathrm{e}^{-} \leftrightarrows \mathrm{NH}_{3}(\mathrm{~g})
\end{gathered}
$$

The perfect catalyst for reaction (2) consists of redox steps that all have an equilibrium potential of $-0.148 \mathrm{~V}$ (i.e. the overall equilibrium potential), or, in the case on non-electrochemical steps, zero reaction free energy. Since on the reversible hydrogen scale, $\Delta G\left(\mathrm{H}^{+}+\mathrm{e}^{-}\right)=0.148 \mathrm{eV}$ at $E=-0.148 \mathrm{~V}$, reactions (7) and (8) can simultaneously have an equilibrium potential of $E=-0.148 \mathrm{~V}$ only if they satisfy the following relation:

$$
\Delta G\left(\mathrm{~N}_{2} \mathrm{H}^{*}\right)-\Delta G\left(\mathrm{NH}_{2}^{*}\right)=0.444 \mathrm{eV}
$$

From reaction (5) and its corresponding equilibrium potential, it follows that $\mathrm{N}_{2} \mathrm{H}^{*}$ needs to bind very strongly for reaction (7) to have to the optimal equilibrium potential. Unfortunately, the binding energies of $\mathrm{NH}_{2}$ and $\mathrm{N}_{2} \mathrm{H}$ are not 
independent, and as a result a strong binding of $\mathrm{N}_{2} \mathrm{H}$ will likely lead to a severe overbinding of $\mathrm{NH}_{2}$, and a corresponding very negative equilibrium potential for reaction (8). This energetic scaling relation between $\mathrm{NH}_{2}{ }^{*}$ and $\mathrm{N}_{2} \mathrm{H}^{*}$ can be estimated as follows. Both $\mathrm{NH}_{2}$ and $\mathrm{N}_{2} \mathrm{H}$ will likely bind to the catalyst through the (free) N. Since both species miss a single electron to be in their nearest stable state, we may estimate that:

$$
\Delta G\left(\mathrm{~N}_{2} \mathrm{H}^{*}\right)-\Delta G\left(\mathrm{NH}_{2}^{*}\right) \approx \Delta G\left(\mathrm{~N}_{2} \mathrm{H}^{-}\right)-\Delta G\left(\mathrm{NH}_{2}{ }^{-}\right)
$$

If we assume that $\mathrm{N}_{2} \mathrm{H}^{-}$and $\mathrm{NH}_{2}{ }^{-}$have comparable solvation energies, and we make use of the fact that the $\mathrm{p} K_{\mathrm{a}} \mathrm{s}$ of $\mathrm{N}_{2} \mathrm{H}_{2}$ and $\mathrm{NH}_{3}$ have been estimated to be very similar, ${ }^{32}$ we have:

$$
\Delta G\left(\mathrm{~N}_{2} \mathrm{H}^{*}\right)-\Delta G\left(\mathrm{NH}_{2}^{*}\right) \approx \Delta G\left(\mathrm{~N}_{2} \mathrm{H}_{2}\right)-\Delta G\left(\mathrm{NH}_{3}\right)
$$

This energy difference can be estimated from the equilibrium potentials of reactions (2) and (4) to be $c a .1 .98 \mathrm{eV}$, significantly different from the "ideal" value of $0.444 \mathrm{eV}$. Below we will see that this simple estimate of $1.98 \mathrm{eV}$ is quite close to the energy difference computed from first-principles DFT calculations. Because it takes four electrons and protons to convert $\mathrm{N}_{2} \mathrm{H}$ to $\mathrm{NH}_{2}$, we can estimate a minimum overpotential of $(1.98 \mathrm{eV}-$ $0.444 \mathrm{eV}) / 4 \mathrm{e}_{0}=c a .0 .4 \mathrm{~V}$. This number comes with a significant uncertainty of at least $0.1 \mathrm{eV}$ due to the various assumptions, but the key point to recognize is that there is a minimum overpotential due to the unfavorable "universal" energetic scaling between intermediates of the reaction, such that the overall thermodynamics of reaction (2) cannot be matched at every stage of the reaction. Very similar conclusions have been reached for the electrocatalytic oxygen reduction, ${ }^{34,35}$ where the unfavorable scaling between the $\mathrm{OOH}$ and $\mathrm{OH}$ intermediates limits the reversibility of even the most optimal catalyst. A reasonable value for this energetic scaling value can be estimated following the reasoning given above (see also ref. 36 and 37), provided the intermediates bind to the catalyst in the same way.

An alternative pathway would avoid the formation of the $\mathrm{N}_{2} \mathrm{H}^{*}$ intermediate through the concerted PCET reaction (7). Note that at sufficiently high $\mathrm{pH}$, reaction (6) may potentially compete with reaction (7), especially if there is a weak binding of $\mathrm{N}_{2} \mathrm{H}^{*}$ and a stabilizing interaction of the catalyst with the $\mathrm{N}_{2}^{-}$intermediate. A similar observation has been made for the oxygen reduction reaction, ${ }^{36}$ where on weakly oxygen binding catalysts (such as gold, carbon and mercury) in alkaline media, the first electron transfer yields a $\mathrm{O}_{2}{ }^{-}(\mathrm{aq})$ intermediate. However, for the oxygen reduction reaction, such a pathway is thermodynamically much more favorable than for the dinitrogen reduction reaction.

\subsection{Theory and mechanism of electrochemical dinitrogen reduction}

The detailed energetics of the various pathways and mechanisms of the (electro-)catalytic dinitrogen reduction can be mapped out by employing first-principles density functional theory (DFT) calculations.

There are several pathways possible wherein dinitrogen is electrochemically reduced to ammonia at a heterogeneous surface. In an associative mechanism, the $\mathrm{N}-\mathrm{N}$ bond is cleaved simultaneously with the release of the first molecule of ammonia, whereas in the dissociative mechanism, the $\mathrm{N} \equiv \mathrm{N}$ bond is broken before any addition of hydrogen occurs. Both the distal and the alternating pathways described in Fig. 2 are variations of an associative pathway. Reduction of dinitrogen by the HaberBosch reaction is generally believed to follow a dissociative pathway. $\mathrm{Ru}$ is the most active catalyst for $\mathrm{N}_{2}$ activation. Cleavage of the $\mathrm{N} \equiv \mathrm{N}$ bond is more facile at a step in the Ru surface than at a flat $\mathrm{Ru}(0001)$ surface. Energy barriers $\left(E_{\mathrm{b}}\right)$ for adsorption have been determined both by experiment and DFT calculations. For a $\mathrm{Ru}(0001)$ surface, $E_{\mathrm{b}}$ lies between 170 and $280 \mathrm{~kJ} \mathrm{~mol}^{-1}$, depending on $\mathrm{N}$ surface coverage. ${ }^{38}$ At stepped $\mathrm{Ru}$ surfaces, the energy barrier for dissociative adsorption is in the order of $60 \mathrm{~kJ} \mathrm{~mol}^{-1} \cdot 39$ Although cleavage of the $\mathrm{N} \equiv \mathrm{N}$ bond is not a facile reaction, the rate determining step under these conditions most likely is the reduction of ${ }^{*} \mathrm{NH}$ to ${ }^{*} \mathrm{NH}_{2}$. An associative mechanism is less favorable at these surfaces, as the addition of the first absorbed hydrogen atom $\left({ }^{*} \mathrm{H}\right)$ to ${ }^{*} \mathrm{~N}_{2}$ to produce ${ }^{*} \mathrm{NNH}$ is difficult.

The dissociative pathway for the electrochemical reduction of dinitrogen at a stepped Ru surface was calculated following the same reaction sequence as shown in Fig. 5. Except for the desorption of ammonia, all steps are downhill in energy at externally applied potentials below $-0.16 \mathrm{~V}$. The potential determining step, i.e. the least exergonic elementary step involving transfer of an electron, is the addition of a proton and an electron to ${ }^{*} \mathrm{NH}_{2}$ to form ${ }^{*} \mathrm{NH}_{3}$. Above a potential of $-0.16 \mathrm{~V}$, this elementary step becomes an uphill reaction and adds to the overall barrier that is necessary to desorb ammonia from the catalytic surface (Fig. 6).

For the electrochemical reduction of dinitrogen at a $\mathrm{Ru}(0001)$ surface also associative pathways were considered. ${ }^{40}$ The potential below which all redox reactions become exergonic is $-1.08 \mathrm{~V}$ on a flat $\mathrm{Ru}(0001)$ surface and $-0.43 \mathrm{~V}$ on a stepped surface. In both cases the distal pathway is preferred over the alternating pathway as the intermediates ${ }^{*} \mathrm{NNH}_{2}$ and ${ }^{*} \mathrm{~N}+\mathrm{NH}_{3}$ are lower in energy than ${ }^{*} \mathrm{NHNH}$ and ${ }^{*} \mathrm{NHNH}_{2} \cdot{ }^{40}$ On the flat surface, the addition of the first proton and electron to ${ }^{*} \mathrm{~N}_{2}$ to form the ${ }^{*} \mathrm{NNH}$ species is the most difficult step. On a stepped surface formation of the ${ }^{*} \mathrm{NNH}$ intermediate is substantially more favorable. This can be explained by stabilization of the ${ }^{*} \mathrm{NNH}$ species by formation of a bond between the distal nitrogen and the terrace as illustrated in Fig. 7. Due to stabilization of the ${ }^{*} \mathrm{NNH}$ species, further reduction

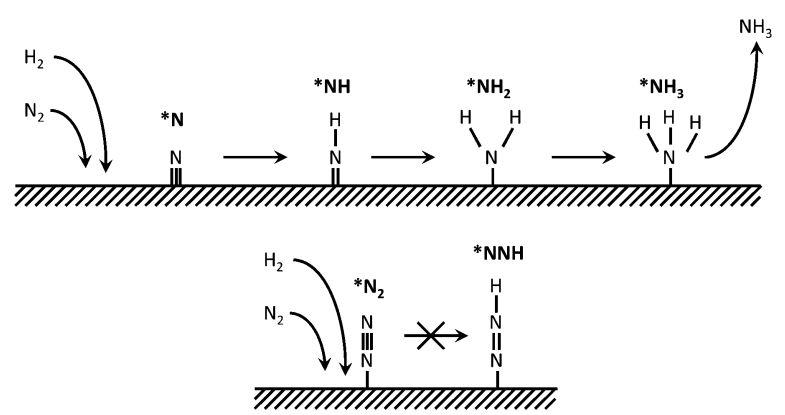

Fig. 5 Reduction of dinitrogen in the Haber-Bosch reaction occurs via an dissociative mechanism (top), whereas a dissociative mechanism is less favorite since addition of the first hydrogen atom is difficult. 


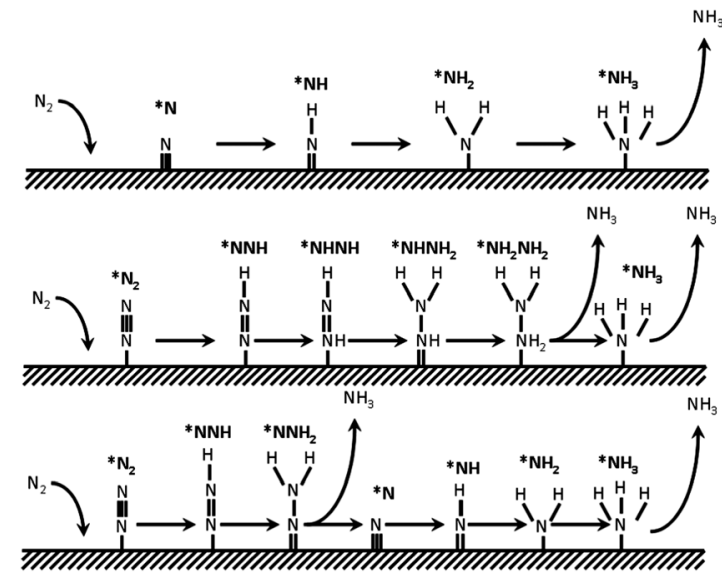

Fig. 6 Reduction of dinitrogen via a dissociative mechanism (top) and associative mechanisms whereby addition of protons occurs via an alternating pathway (middle) and a distal pathway (bottom), upon addition of protons and electrons at a heterogeneous surface.

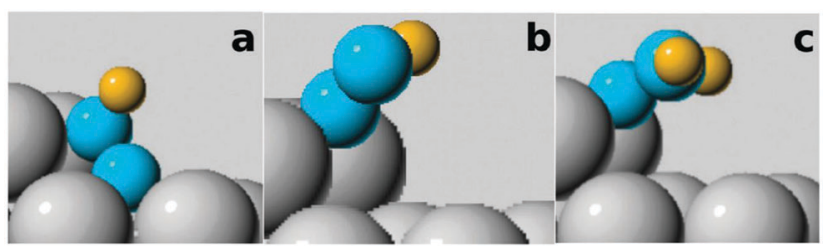

Fig. 7 Coordination mode of * $\mathrm{NNH}$ (a and b) and ${ }^{*} \mathrm{NNH}_{2}$ (c) to a step on a $\mathrm{Ru}(0001)$ surface. In case of ${ }^{*} \mathrm{NNH}$ configuration (a) is more stable than configuration (b). Reproduced from ref. 40 with permission from the PCCP Owner Societies.

of ${ }^{*} \mathrm{NNH}$ to ${ }^{*} \mathrm{NNH}_{2}$ is more cumbersome and hence formation of this latter species is the potential determining step at a stepped Ru surface. In summary, the dissociative mechanism for the reduction of dinitrogen at stepped Ru surface requires the least external driving force. However, since cleavage of the $\mathrm{N} \equiv \mathrm{N}$ bond on the surface proceeds over a large activation barrier, this pathway can only produce substantial amounts of ammonia at elevated temperatures. The distal associative pathway becomes available at more negative potentials. In this pathway desorption of ammonia is most likely the rate limiting factor and catalysis may proceed at a lower temperature.

The preferred mechanism by which catalysis can take place varies with the choice of metal. Nørskov and coworkers compared the catalytic properties of a series of metal surfaces in a volcano plot (Fig. 8). ${ }^{40}$ Herein the minimum potential that is required to undergo the most difficult step in the catalytic cycle is depicted for a series of metals. For such volcano plots the energy of every intermediate is calculated and the $-\Delta G$ of the potential determining step is plotted versus the nitrogen binding energy. Using a single "descriptor" is possible because the binding energies of $\mathrm{NH}_{x}{ }^{*}$ and $\mathrm{N}_{2} \mathrm{H}_{x}{ }^{*}$ scale in a linear fashion with the binding energy of $\mathrm{N}^{*}$. By determining the scaling relationships between either $\mathrm{NH}_{x}^{*}$ or $\mathrm{N}_{2} \mathrm{H}_{x}^{*}$ and $\mathrm{N}^{*}$, the overpotential requirement of different metals with different potential determining steps are obtained. At high binding energies of $\mathrm{N}^{*}$, the dissociative

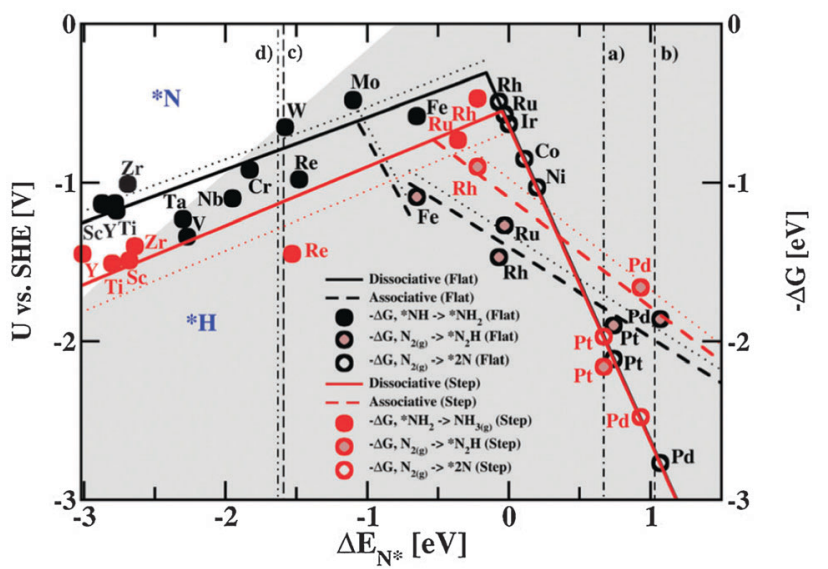

Fig. 8 Volcano plot of electrochemical reduction of dinitrogen via a dissociative mechanism on a flat surface (black solid line), associative mechanism on a flat surface (black dotted line), dissociative mechanism on a stepped surface (red solid line) and associative mechanism on a stepped surface (red dotted line) for a selected series of metals. The diagram gives the minimum potential that needs to be applied to overcome the most difficult redox reaction of the sequence of reaction steps in the catalytic mechanism ( $y$-axis) for a series of metals that are plotted as a function of nitrogen absorption strength ( $x$-axis). The redox potential limiting step in the catalytic cycle for every metal that was calculated is highlighted by circles. In the grey area adsorption of * $\mathrm{H}$ is favored over ${ }^{*} \mathrm{~N}$ and selectivity problems due to formation of $\mathrm{H}_{2}$ besides formation of $\mathrm{NH}_{3}$ formation can be expected. Reproduced from ref. 40 with permission from the PCCP Owner Societies.

mechanism at flat surfaces is favored. The potential determining step is the addition of the second proton-electron couple, from $\mathrm{NH}^{*}$ to $\mathrm{NH}_{2}{ }^{*}$. At stepped surfaces and intermediate $\mathrm{N}^{*}$ binding energy, the dissociative mechanism on stepped Rh surfaces is most efficient. The potential determining step is the final PCET and the release of the ammonia. At slightly weaker binding energies of $\mathrm{N}^{*}$, the dissociative mechanism on flat surfaces is still prevailing, but the dissociation of dinitrogen is potential determining. At weak binding energies, the associative mechanism becomes favourable. The potential determining step is the addition of the first proton to the dinitrogen on both flat and stepped surfaces. Slightly lower potentials are required for flat ruthenium and rhodium surfaces compared to stepped surfaces, yet cleavage of the $\mathrm{N}-\mathrm{N}$ bond on a flat surface proceeds over a huge kinetic barrier and therefore is not expected to occur at mild temperatures. In a similar fashion the volcano plots for the reduction of dinitrogen for an associative mechanism were calculated for flat and stepped surfaces (Fig. 8). ${ }^{40}$ On flat surfaces and low binding energies for $\mathrm{N}^{*}$ the associative pathway is limited by addition of the first proton and electron to free dinitrogen. In case of the earlier transition metals, addition of dinitrogen and its protonation become more facile and the redox potential is limited by reduction of ${ }^{*} \mathrm{NH}$ to ${ }^{*} \mathrm{NH}_{2}$ and ${ }^{*} \mathrm{NH}_{2}$ to $\mathrm{NH}_{3}$. Molybdenum appears to be the most optimal catalyst for this pathway and is predicted to require only a slightly negative potential for all elementary steps to become feasible. At a stepped surface formation and desorption of ammonia is a problem and for this type of surface ruthenium appears to be the most optimal catalyst. However a larger overpotential is required compared to a flat 
molybdenum surface. ${ }^{40}$ It is important to note that these volcano plots only consider the relative energies of the catalytic intermediates and not the kinetic barriers between them.

Note from Fig. 8 that there is no catalyst with zero overpotential. The lowest overpotential is $c a$. $0.4 \mathrm{~V}$ in very good agreement with the estimate in Section 4.1. The energetic scaling between intermediates is the reason for this overpotential.

\subsection{Catalytic systems}

In order quantify the efficiency of electrochemical systems, the electric energy input to make one mole of $\mathrm{NH}_{3}$ must be calculated. This quantity can be calculated using eqn (12), in which $E$ is the consumption of electrical energy for the reaction in $\mathrm{kJ} \mathrm{mol}^{-1}$, $j$ is the current density in $\mathrm{mA} \mathrm{cm}^{-2}, U$ is the total cell potential in $\mathrm{V}$ and $r_{\mathrm{NH}_{3}}$ is the production rate of ammonia in mol s${ }^{-1} \mathrm{~cm}^{-2}$.

$$
E=\frac{j \times U}{r_{\mathrm{NH}_{3}} \times 10^{6}}
$$

Few electrochemical systems that produce convincing amounts of ammonia have been reported. Based on the DFT calculations described above, Ru should be the best catalyst for the reduction of $\mathrm{N}_{2}$ to ammonia. In 2000, Kordali et al. reported a $\mathrm{Ru}$ cathode on a carbon felt in a three electrode setup at low temperature and atmospheric pressure. ${ }^{41}$ At a cathode potential of $0.06 \mathrm{~V} v s$. RHE, ammonia production started. Since the equilibrium potential under the conditions used was just $0.14 \mathrm{~V}$, a small overpotential of $0.08 \mathrm{~V}$ is required to start the reaction. The maximum rate of the reaction is $2.0 \times 10^{-11} \mathrm{~mol} \mathrm{~s}^{-1} \mathrm{~cm}^{-2}$ at $0.00 \mathrm{~V}$ and $90{ }^{\circ} \mathrm{C}$. The highest current efficiency was achieved at $0.06 \mathrm{~V}$ and $90{ }^{\circ} \mathrm{C}$ and was calculated to be $0.92 \%$. The limiting factors are the hydrogen evolution reaction (HER) and low ammonia production rate.

In 2013, Lan et al. ${ }^{42}$ described a catalytic system with both a Pt cathode and anode, in combination with a Nafion 211 membrane. At a total cell potential of $0.2 \mathrm{~V}$ and using air as a feedstock, a maximum production rate of $3.5 \times 10^{9} \mathrm{~mol} \mathrm{~s}{ }^{-1} \mathrm{~cm}^{-2}$ was obtained. The faradaic efficiency of this system is $0.7 \%$, which decreases when the potential is further increased. Most likely, the evolution of hydrogen and reduction of oxygen are competing side reactions that limit the efficiency of the ammonia synthesis. Using dinitrogen as a feedstock instead of air results in an increase of the faradaic efficiency to $2 \%$, confirming that the presence of oxygen is a problem. The total energy consumption of the ammonia synthesis from dihydrogen and air is $8.3 \times 10^{3} \mathrm{~kJ} \mathrm{~mol}^{-1}$ for the experiment at $0.2 \mathrm{~V}$.

The results for both the $\mathrm{Ru}$ and $\mathrm{Pt}$ electrocatalysts are in disagreement with the theoretical evaluation for an associative mechanism as described in Sections 4.1 and 4.2, in which the minimal overpotential is estimated to be $c a .400 \mathrm{mV}$. Such overpotentials are generally observed for other multiple PCET reactions such as oxygen reduction. ${ }^{4,44}$ The observation of ammonia production at such low overpotentials or low cell potentials is highly unexpected. Moreover, note that the analysis in Fig. 8 predicts $\mathrm{Ru}$ and $\mathrm{Pt}$ to be better $\mathrm{H}_{2}$ evolution catalysts than $\mathrm{N}_{2}$ reduction catalysts. Catalytic reduction of dinitrogen via a dissociative mechanism is not likely either, as this reaction must proceed via a large barrier due to cleavage of the $\mathrm{N} \equiv \mathrm{N}$ bond.
Cleavage of the $\mathrm{N} \equiv \mathrm{N}$ bond may be feasible at elevated temperatures. The first report of electrochemical ammonia synthesis under an atmospheric pressure of dihydrogen and dinitrogen at elevated temperature was described by Marnellos and Stoukides in $1998 .{ }^{45}$ In the solid state electrochemical cell two palladium electrodes are separated by the proton conducting electrolyte $\mathrm{SrCe}_{0.95} \mathrm{Yb}_{0.05} \mathrm{O}_{3}$ (SCY). The authors report that at least $78 \%$ of the dihydrogen supplied was transformed into ammonia. At ambient pressure, the electrochemical cell was reported to produce more than three orders of magnitude higher ammonia concentrations at $570{ }^{\circ} \mathrm{C}$ than the conventional Haber-Bosch cell. Since for this system no potentials were reported, the total energy consumption could not be determined.

$$
\begin{gathered}
\mathrm{N}_{2}+6 \mathrm{H}^{+}+6 \mathrm{e}^{-} \rightarrow 2 \mathrm{NH}_{3} \\
\mathrm{H}_{2} \rightarrow 2 \mathrm{H}^{+}+2 \mathrm{e}^{-}
\end{gathered}
$$

Amar et al. used the rather complex perovskite $\mathrm{La}_{0.6} \mathrm{Sr}_{0.4} \mathrm{Fe}_{0.8}$ $\mathrm{Cu}_{0.2} \mathrm{O}_{3-\delta}$ as a cathode. ${ }^{46}$ At $0.8 \mathrm{~V}$ total cell potential, a maximum production rate in ammonia of $5.39 \times 10^{-9} \mathrm{~mol} \mathrm{~s}^{-1} \mathrm{~cm}^{-2}$ was obtained at $450{ }^{\circ} \mathrm{C}$. At higher temperatures the rates drop as a result of an increased decomposition rate of ammonia or an increased production rate of dihydrogen at these elevated temperatures. Since the current increased with increasing potential, it seems likely that hydrogen production is the rate limiting factor. Under optimal conditions a steady state current of $52 \mathrm{~mA} \mathrm{~cm} \mathrm{~cm}^{-2}$ and a faradaic efficiency of $1 \%$ was observed. With eqn (12), one can calculate that an energy input of $7.7 \times 10^{3} \mathrm{~kJ} \mathrm{~mol}^{-1}$ is required for the synthesis of ammonia via this procedure.

In 2005, Murakami and coworkers reported the electrochemical synthesis of ammonia from water and dinitrogen at high temperature in molten salts at atmospheric pressure. ${ }^{47}$ The experimental setup and reactions involved significantly differ from the processes described above. At the cathode, dinitrogen is transformed to nitrido ions (eqn (15)). In the molten electrolyte the nitrido ions react with water, producing ammonia and oxide ions (eqn (16)). The oxide is subsequently oxidized at the anode (eqn (17)).

$$
\begin{gathered}
\mathrm{N}_{2}+6 \mathrm{e}^{-} \rightarrow 2 \mathrm{~N}^{3-} \\
2 \mathrm{~N}^{3-}+3 \mathrm{H}_{2} \mathrm{O} \rightarrow 2 \mathrm{NH}_{3}+3 \mathrm{O}^{2-} \\
2 \mathrm{O}^{2-} \rightarrow \mathrm{O}_{2}+4 \mathrm{e}^{-}
\end{gathered}
$$

Thus the formation of ammonia in this system occurs in the molten electrolyte salt rather than at one of the electrodes. The authors report that roughly $90 \%$ of water was converted in a productive reaction to ammonia with a faradaic efficiency of $23 \%$. Major bottlenecks that limit the faradaic efficiency are regeneration of dinitrogen from two equivalents of nitrido ions at the anode, and formation of hydroxide from oxide ions and water. The system is less efficient than the Haber-Bosch process with an electrical energy consumption of $3.1 \times 10^{3} \mathrm{~kJ} \mathrm{~mol}^{-1}$.

Recently, the photoelectrochemical synthesis of ammonia under ambient pressure and temperature by diamond was reported. ${ }^{48}$ Upon irradiation of diamond with UV, high energy solvated electrons are liberated from the diamond to the electrolyte, 
where protons are reduced to hydrogen radicals. These are proposed to react with dinitrogen to form diazenyl radicals, which eventually leads to formation of ammonia. Absorption of dinitrogen to the surface is not necessary and consequently there is no competition with adsorption of hydrogen at the surface. This may lead to an improved selectivity. However, faradaic efficiencies were not reported.

\section{Can electrochemical reduction of dinitrogen be an alternative to the Haber-Bosch reaction?}

Dissociative, distal associative and alternating associative mechanisms have been proposed for several nitrogen fixation systems. Only in few cases direct experimental evidence is available that shows which mechanism prevails. Catalytic reduction of dinitrogen in case of the Schrock catalyst occurs via a distal associative mechanism. Also in case of nitrogenases, it seems very likely that an associative pathway is followed. This does not imply that in case of molecular systems a dissociative pathway is not possible. Cummins and coworkers reported a molybdenum trisamido system that is remarkably similar to the Schrock catalyst, and allows for direct cleavage of the $\mathrm{N} \equiv \mathrm{N}$ bond in a bimolecular fashion, which leads to formation of two molybdenum nitride species. ${ }^{49}$ However, production of ammonia was not reported for these species. In contrast to the molecular systems, our understanding of the dinitrogen reduction process on heterogeneous surfaces relies fully on theoretical calculations, as experimental evidence is unavailable. These calculations suggest that in case of a dissociative mechanism on a stepped surface, rhodium and ruthenium are the best candidates, whereas on a flat surface the barriers for $\mathrm{N} \equiv \mathrm{N}$ bond cleavage are very high. Ruthenium and rhodium also perform well on stepped surfaces via an associative pathway. Flat surfaces of molybdenum and tungsten would appear ideal for nitrogen fixation via an associative pathway. Unfortunately, our understanding of electrochemical nitrogen reduction on heterogeneous surfaces is very limited. More experimental evidence, especially at low temperature, is needed to improve our understanding of the reaction. Suppression of the HER is one of the major challenges that must be overcome.

Simultaneous formation of dihydrogen is indeed a major concern, and even the natural systems show poor selectivities. ${ }^{11}$ Especially in case of $\mathrm{FeV}$ and Fe only nitrogenases large amounts of hydrogen are produced. Typically enzymatic reactions are selective, illustrating that this selectivity issue is a difficult problem. It is therefore quite remarkable that the single site catalysts described by Schrock, Nishibayashi and Peters produce relatively little hydrogen. ${ }^{18,25,28}$

Selectivity is a much larger issue on heterogeneous surfaces. Especially in case of late transition metal surfaces, formation of dihydrogen upon reduction of protons is a facile reaction that requires very little overpotential. To prevent this, a metal is required that has a much stronger ${ }^{*} \mathrm{~N}$ binding energy compared to the ${ }^{*} \mathrm{H}$ binding energy. This requires deviation of the optimal catalyst according the volcano plots and significant larger potentials may be required to produce sufficient amounts of ammonia. Elevated temperatures must be prevented as these are likely to result in decomposition of ammonia to regenerate dihydrogen. Dissociative mechanisms proceed via high barriers to achieve $\mathrm{N} \equiv \mathrm{N}$ bond cleavage and therefore may not be the most suitable pathway.

Formation of dihydrogen does not only occur as an independent side reaction, but may also compete with reduction of dinitrogen via decomposition of partly reduced intermediates. Controlling the surface coverage of ${ }^{*} \mathrm{H}$ and ${ }^{*} \mathrm{~N}$ alone may not be sufficient to win the selectivity battle. In the biological systems, for example, formation of dihydrogen seems to be obligatory to produce ammonia. ${ }^{15,50}$ In case of the Schrock system it was established that the Mo-NNH species is unstable and unless $\beta$ elimination is sterically prohibited, dihydrogen is produced in a fast reaction wherein the Mo- $\mathrm{N}_{2}$ species is regenerated. ${ }^{23}$

Despite the large energy consumption that is used for the Haber-Bosch reaction, the process is quite efficient in ammonia production in terms of energy usage. Nitrogenases consume half the energy of the Haber-Bosch process in ATP, whereas artificial systems consume substantially more energy. Note that the numbers for the Haber-Bosch reaction were calculated for the entire reaction process, including production of hydrogen and pressurizing the gasses.

Molecular dinitrogen reduction catalysts are very valuable for understanding the catalytic processes that underlie catalytic reduction of dinitrogen. Yet due to their poor stability and low reaction rates so far molecular catalysts are of little use in large scale dinitrogen conversion processes. Likewise diazotrophic microorganisms that can fixate dinitrogen using nitrogenases consume large amounts of energy for e.g. growth and maintenance. Also electrochemical alternatives require a substantially larger energy input compared to the Haber-Bosch reaction. This is mainly caused by poor faradaic efficiencies, resulting in energy loss due to formation of dihydrogen. It is not unlikely that progress can be made in this area by suppressing hydrogen formation and minimizing the required potential. Taking the volcano plots in Fig. 7 into consideration, one can calculate that a substantial amount of energy will be required to produce ammonia electrochemically (eqn (12)), even if $100 \%$ faradaic efficiencies are obtained. The volcano plot in Fig. 7 shows that no catalytic activity is expected above $-0.5 \mathrm{~V}$ for the metal surfaces considered. This already equals an energy input of $288 \mathrm{~kJ} \mathrm{~mol}^{-1}$ and thus leaves very little room to spare.

Electrochemical production of ammonia without consumption of large amounts of energy is extremely challenging and requires development of new catalytic systems. Recently, major hurdles have been taken in (1) our understanding of the nitrogen fixation process by nature, (2) how to reduce dinitrogen at molecular inorganic systems and (3) electrochemical dinitrogen reduction at heterogeneous surfaces. Yet, a much better fundamental understanding of reduction of $\mathrm{N}_{2}$ upon addition of protons and electrons is necessary to make the next steps towards efficient electrocatalytic reduction of dinitrogen. New catalysts, which have a preference of ${ }^{*} \mathrm{~N}$ over ${ }^{*} \mathrm{H}$ and at 
which all catalytic steps are feasible at mild potentials, must be found. So far experimental and theoretical screening of catalysts has been limited to few materials only. For now it seems that the Haber-Bosch reaction will remain the dominating means of industrial ammonia production for quite some time...

\section{Notes and references}

1 V. Rosca, M. Duca, M. T. de Groot and M. T. M. Koper, Chem. Rev., 2009, 109, 2209-2244.

2 B. K. Burgess and D. J. Lowe, Chem. Rev., 1996, 96, 2983-3011.

3 D. R. Lide, CRC Handbook of Chemistry and Physics, Internet version 2005, CRC Press, 2005.

4 V. Smil, Enriching the Earth: Fritz Haber, Carl Bosch, and the Transformation of World Food Production, MIT Press, 2004.

5 M. Appl, Ullmann's Encyclopedia of Industrial Chemistry, Wiley-VCH Verlag GmbH \& Co. KGaA, 2006.

6 This energy includes the entire process and includes e.g. hydrogen production using steam reforming, pressurizing of the reaction mixture, etc.

7 O. Einsle, F. A. Tezcan, S. L. A. Andrade, B. Schmid, M. Yoshida, J. B. Howard and D. C. Rees, Science, 2002, 297, 1696-1700.

8 T. Spatzal, M. Aksoyoglu, L. M. Zhang, S. L. A. Andrade, E. Schleicher, S. Weber, D. C. Rees and O. Einsle, Science, 2011, 334, 940.

9 K. M. Lancaster, M. Roemelt, P. Ettenhuber, Y. L. Hu, M. W. Ribbe, F. Neese, U. Bergmann and S. DeBeer, Science, 2011, 334, 974-977.

10 A. Lehninger, D. Nelson and M. Cox, Lehninger Principles of Biochemistry, W. H. Freeman, 2008.

11 F. B. Simpson and R. H. Burris, Science, 1984, 224, 1095-1097.

12 B. F. Hoffman, D. Lukoyanov, Z.-Y. Yang, D. R. Dean and L. C. Seefeldt, et al., Chem. Rev., 2014, 114, 4041.

13 S. Wherland, B. K. Burgess, E. I. Stiefel and W. E. Newton, Biochemistry, 1981, 20, 5132-5140.

14 B. K. Burgess, S. Wherland, W. E. Newton and E. I. Stiefel, Biochemistry, 1981, 20, 5140-5146.

15 L. C. Seefeldt, B. M. Hoffman and D. R. Dean, Annu. Rev. Biochem., 2009, 78, 701-722.

16 M. J. Dilworth and R. R. Eady, Biochem. J., 1991, 277, 465-468.

17 J. Chatt, J. R. Dilworth and R. L. Richards, Chem. Rev., 1978, 78, 589-625.

18 D. V. Yandulov and R. R. Schrock, Science, 2003, 301, 76-78.

19 D. V. Yandulov and R. R. Schrock, J. Am. Chem. Soc., 2002, 124, 6252-6253.

20 D. V. Yandulov and R. R. Schrock, Inorg. Chem., 2005, 44, 1103-1117.

21 R. R. Schrock, Angew. Chem., Int. Ed., 2008, 47, 5512-5522.

22 W. W. Weare, X. L. Dai, M. J. Byrnes, J. M. Chin, R. R. Schrock and P. Muller, Proc. Natl. Acad. Sci. U. S. A., 2006, 103, 17099-17106.
23 W. W. Weare, R. R. Schrock, A. S. Hock and P. Muller, Inorg. Chem., 2006, 45, 9185-9196.

24 D. G. H. Hetterscheid, B. S. Hanna and R. R. Schrock, Inorg. Chem., 2009, 48, 8569-8577.

25 K. Arashiba, Y. Miyake and Y. Nishibayashi, Nat. Chem., 2011, 3, 120-125.

26 F. Neese, Angew. Chem., Int. Ed., 2006, 45, 196-199.

27 Y. Lee, N. P. Mankad and J. C. Peters, Nat. Chem., 2010, 2, 558-565.

28 J. S. Anderson, J. Rittle and J. C. Peters, Nature, 2013, 501, 84-87.

29 N. Hazari, Chem. Soc. Rev., 2010, 39, 4044-4056.

30 K. C. MacLeod and P. L. Holland, Nat. Chem., 2013, 5, 559-565.

31 H.-P. Jia and E. A. Quadrelli, Chem. Soc. Rev., 2014, 43, 547-564.

32 N. Bauer, J. Phys. Chem., 1960, 64, 833-837.

33 A. E. Shilov, Russ. Chem. Bull., 2003, 52, 2555-2562.

34 M. T. M. Koper, J. Electroanal. Chem., 2011, 660, 254-260.

35 I. C. Man, H.-Y. Su, F. Calle-Vallejo, H. A. Hansen, J. I. Martínez, N. G. Inoglu, J. Kitchin, T. F. Jaramillo, J. K. Nørskov and J. Rossmeisl, ChemCatChem, 2011, 3, 1159-1165.

36 M. T. M. Koper, Chem. Sci., 2013, 4, 2710-2723.

37 V. Viswanathan and H. Hansen, Top. Catal., 2014, 57, 215-221.

38 L. Diekhöner, H. Mortensen, A. Baurichter and A. C. Luntz, J. Chem. Phys., 2001, 115, 3356-3373.

39 T. H. Rod, A. Logadottir and J. K. Norskov, J. Chem. Phys., 2000, 112, 5343-5347.

40 E. Skulason, T. Bligaard, S. Gudmundsdottir, F. Studt, J. Rossmeisl, F. Abild-Pedersen, T. Vegge, H. Jonsson and J. K. Norskov, Phys. Chem. Chem. Phys., 2012, 14, 1235-1245.

41 V. Kordali, G. Kyriacou and C. Lambrou, Chem. Commun., 2000, 1673-1674.

42 R. Lan, J. T. S. Irvine and S. W. Tao, Int. J. Hydrogen Energy, 2012, 37, 1482-1494.

43 J. K. Norskov, J. Rossmeisl, A. Logadottir, L. Lindqvist, J. R. Kitchin, T. Bligaard and H. Jonsson, J. Phys. Chem. B, 2004, 108, 17886-17892.

44 H. A. Gasteiger, S. S. Kocha, B. Sompalli and F. T. Wagner, Appl. Catal., B, 2005, 56, 9-35.

45 G. Marnellos and M. Stoukides, Science, 1998, 282, 98-100. 46 I. A. Amar, C. T. G. Petit, L. Zhang, R. Lan, P. J. Skabara and S. Tao, Solid State Ionics, 2011, 201, 94-100.

47 T. Murakami, T. Nohira, T. Goto, Y. H. Ogata and Y. Ito, Electrochim. Acta, 2005, 50, 5423-5426.

48 D. Zhu, L. H. Zhang, R. E. Ruther and R. J. Hamers, Nat. Mater., 2013, 12, 836-841.

49 C. E. Laplaza and C. C. Cummins, Science, 1995, 268, 861-863.

50 B. M. Hoffman, D. Lukoyanov, D. R. Dean and L. C. Seefeldt, Acc. Chem. Res., 2013, 46, 587-595. 